\title{
Resenha
}

\section{Os limites da democracia dos Estados Unidos}

Tiago Santos Salgado ${ }^{1}$

\section{LEVITSKY, Steven; ZIBLATT, Daniel. Como as democracias morrem. Rio de Janeiro: Zahar, 2018.}

A obra Como as democracias morrem, dos professores de Harvard Steven Levitsky e Daniel Ziblatt, publicada no Brasil em 2018, chamou a atenção do público brasileiro, uma vez que, buscando compreender os riscos que a democracia dos Estados Unidos estava correndo com a eleição de Donald Trump, tocava em aspectos caros a corrida eleitoral que estava em curso no país, corrida esta que acabou com a eleição de Jair Bolsonaro, que se não é o “Trump da América do sul”, como o próprio estadunidense colocou em entrevista em janeiro de $2019^{2}$, buscou emular características discursivas e propositivas que estiveram e estão presentes na campanha presidencial e no governo do atual presidente dos Estados Unidos.

Portanto, dentro do ambiente polarizado que marcou a corrida presidencial no Brasil que acarretou a vitória do candidato que publicamente defende a ditadura militar e a supressão de direitos dos trabalhadores e das minorias, a ideia presente no livro de que a democracia pode ser "morta" através de processos eleitorais vencidos por autocratas, ou seja, sem a necessidade de tanques nas ruas ou da participação direta das Forças Armadas, ia ao encontro dos anseios analíticos de parte da opinião pública que buscava entender as contingências históricas que levaram ao conhecido resultado nas urnas.

Escrito em uma linguagem acessível, recheado de exemplos que conseguem explicar as tramas políticas e os contextos históricos de forma simples e mesmo sendo um estudo dedicado ao caso específico dos Estados Unidos, que segundo Levitsky e Ziblatt, possuem uma espécie de excepcionalidade democrática, as análises dos autores parecem cair como uma luva na realidade brasileira para quem buscava compreender as nuances e as particularidades que colocavam em risco nossa democracia.

Tal excepcionalidade da democracia estadunidense repousa, para os autores, em vários fatores, em especial na existência de duas regras que sempre foram respeitadas pelos políticos locais, mesmo que não previstas constitucionalmente, que garantem o sistema de pesos e contrapesos e a funcionalidade democrática, construindo assim uma espécie de proteção

1 Doutorando pela Pontifícia Universidade Católica de São Paulo (PUC-SP). E-mail: tiago_salgado1986@hotmail.com.

2 Disponível em: <https://noticias.uol.com.br/ultimas-noticias/afp/2019/01/14/trumpelogia-bolsonaro-o-donald-trump-da-america-do-sul.htm>. 
contra tentativas autoritárias. Essas duas regras seriam a tolerância mútua e a reserva institucional. A primeira delas é a ideia de que os adversários políticos entendem que, respeitando as regras, todos possuem o direito de competir pelo poder e governar, mesmo que não concordem com suas ideias e projetos de nação (2018, p. 104). A segunda significa "autocontrole paciente, comedimento e tolerância, ou a ação de limitar o uso de um direito legal", sendo a reserva institucional o

ato de evitar ações que, embora respeitem a letra da lei, violam claramente o seu espírito. Quando normas de reserva são robustas, políticos não usam suas prerrogativas institucionais até o limite, mesmo que tenham o direito legal de fazê-lo, pois tal ação pode pôr em perigo o sistema existente (2018, p. 107)

Quer dizer, dentro da perspectiva da reserva legal e da tolerância mútua, os governos deveriam evitar o aparelhamento do judiciário, a perseguição a jornalistas e a oponentes políticos, ou buscar expedientes extremos, como o impeachment para conseguir seus objetivos políticos, não porque são ilegais, mas porque prejudicam a existência e o funcionamento do sistema democrático.

Estas duas normas, coadunadas com o funcionamento adequado do Judiciário, do Legislativo e do Executivo através da ação dos "guardiões da democracia” (2018, p. 34), ou seja, dos partidos políticos, das elites e das instituições (2018, p. 46), haviam impedido que eventos como a crise de 1929 ou o macarthismo acabassem com a democracia norte-americana, que agora estava ameaçada graças a falta de reserva institucional e tolerância mútua encarnadas por Donald Trump, membros do Partido Republicano e parcela da mídia.

(...) quando a democracia norte-americana funcionou, ela se baseou em duas normas que nós muitas vezes tomamos como naturais - tolerância mútua e reserva institucional. Tratar rivais como concorrentes legítimos e subutilizar prerrogativas institucionais próprias no espírito do jogo limpo são regras não escritas na Constituição dos Estados Unidos (2018, p. 201)

Estes são, de forma resumida, os principais pontos discutidos na obra. Como é possível perceber, não foi por acaso o livro chamou a atenção no Brasil, tendo em vista as discussões que marcaram a campanha eleitoral brasileira. No entanto, a obra acaba por apresentar uma definição de democracia que não abarca a totalidade das nuances e da extensão que a prática democrática pressupõe. Para validar o argumento central do livro, ou seja, de que a democracia dos Estados Unidos apresentou "barreiras democráticas" contra líderes autoritários, os autores constroem uma espécie de tipo ideal de democracia - considerada um valor universal -, sendo entendida como um enquadramento formal e institucional predeterminados, não importando as particularidades históricas e a concretude social existentes em diferentes momentos. 
Ao realizar tal operação, Ziblatt e Levitsky buscam identificar um caminho comum que explica a supressão democrática em ambientes tão diversos como a Venezuela chavista, a Itália fascista e a Alemanha nazista. Para os autores, em momentos de crise econômica e política, os "guardiões da democracia”, em especial as elites, fazem uma "aliança fatídica” com líderes autoritários que resultam na supressão democrática através das próprias normas legais previstas nas democracias liberais do ocidente.

\begin{abstract}
Apesar de suas enormes diferenças, Hitler, Mussolini e Chávez percorreram caminhos que compartilham semelhanças espantosas para chegar ao poder. Não apenas todos eles eram outsiders com talento para capturar a atenção pública, mas cada um deles ascendeu ao poder porque políticos do establishment negligenciaram os sinais de alerta e, ou bem lhes entregaram o poder (Hitler e Mussolini), ou então lhes abriram a porta (Chávez). (2018, p. 29)
\end{abstract}

Explicar a história política da Itália fascista, da Alemanha nazista e da Venezuela chavista através do prisma da aliança entre as elites e líderes autoritários que configuram uma ameaça ao sistema democrático em momentos de crise é, no mínimo, problemático, uma vez que inviabiliza discussões de fundo, ou seja, sobre as próprias particularidades históricas dos fenômenos analisados. Ora, apenas sob o viés traçado pelos autores, que é essencialmente politicista, já que ignora qualquer dinâmica social de classe, é possível colocar no mesmo arcabouço conceitual experiências tão diferentes como as citadas. No livro, outros momentos e contextos históricos são comparados, como o Equador de Rafael Correia, a Argentina de Perón e o Peru de Fujimori, todas experiências diversas, que são analisadas como se fossem iguais.

Outro aspecto que salta aos olhos na obra é a perspectiva universal que os autores conferem a democracia liberal, ou seja, mesmo que tal perspectiva não esteja citada textualmente, a ideia de que a democracia liberal é a única saída para as sociedades contemporâneas pode ser percebida no texto, uma vez que, para os autores, os países que não se encaixam no tipo ideal traçado são considerados autoritários. Não existe meio termo, ou se é uma democracia, como a dos Estados Unidos, ou se é caracterizado como autoritário.

Ou seja, não é qualquer democracia que é considerada universal, mas o modelo de democracia liberal existente nos Estados Unidos, que deve ser seguido e copiado pelo resto do mundo. Por isso o alarde com a ameaça representada por Donald Trump, uma vez que a defesa da democracia faz parte do próprio corolário de dominação dos Estados Unidos em âmbito internacional.

Nesse sentido, cabe discutir quais são as características marcantes da democracia dos Estados Unidos que a torna excepcional. Algumas delas 
já foram discutidas acima, como o funcionamento dos pesos e contrapesos, o funcionamento apropriado dos três poderes, a tolerância mútua e a reserva institucional e a importância dos "guardiões da democracia". Como para os autores os principais agentes democráticos são as elites e os partidos, chama a atenção que a presença das classes populares, dos trabalhadores, das minorias, dos movimentos sociais não faça parte dessa excepcionalidade democrática, as classes populares necessárias apenas para a consulta eleitoral.

$\mathrm{Na}$ obra, o ideal é a existência de uma democracia sem povo, ou melhor, com pouco povo, controlada essencialmente por uma elite política com a missão de fiscalizar e impedir que o povo eleja autoritários personalistas e carismáticos. Nesse sentido, a democracia dos Estados Unidos começou a entrar em risco no final da década de 1960, quando os dois grandes partidos do país, o Republicano e o Democrata, passaram a abrir as votações primárias, o que impedia que os líderes partidários controlassem as indicações para a candidatura presidencial.

O caminho para a indicação não tinha mais que passar pelo establishment do partido. Pela primeira vez, os guardiões dos portões da democracia podiam ser contornados e derrotados. [...] Alguns cientistas políticos se mostraram preocupados com o novo sistema. Primárias vinculantes eram certamente mais democráticas. Mas não seriam democráticas demais? Ao colocar as indicações presidenciais nas mãos dos eleitores, as primárias vinculantes enfraqueceram a função dos partidos como guardiões da democracia, eliminando potencialmente 0 processo de revisão por pares e abrindo a porta para outsiders.

Outro ponto importante para se compreender os limites da conceitualização de democracia proposta na obra é a questão racial nos Estados Unidos. Os autores alegam que a democracia no país vem se construindo desde a formação do estado nacional estadunidense, ou seja, mesmo com a existência da escravidão e, posteriormente, com a existências de leis segregacionistas que existiram até a segunda metade do século XX. Levitsky e Ziblatt admitem que o acordo que consolidou a democracia nos Estados Unidos no século XIX só foi possível em função do impedimento da participação negra na vida política do país através de diversos dispositivos legais, uma vez que apenas dessa forma foi possível costurar um consenso entre as elites econômicas e políticas dos estados do sul e do norte do país. Mesmo com as reformas dos anos de 1960, tal fato causa uma espécie de déficit democrático no país, que deve ser enfrentado e superado.

A fundação da república norte-americana deixou a dominação racial intacta, o que acabou levando à Guerra Civil. Quando democratas e republicanos finalmente se reconciliaram na esteira da fracassada Reconstrução, sua reconciliação se baseou mais uma vez na exclusão racial. As reformas dos anos de 1960 
deram ao país uma terceira chance de construir uma democracia verdadeiramente multiétnica. É imperativo que consigamos, embora seja uma tarefa de extraordinária dificuldade (2018, p. 214).

A questão aqui não é o reconhecimento por parte dos autores de que a democracia dos Estados Unidos se deu através de um forte aspecto de segregação racial. Isso seria negar a própria realidade. Mas sim o fato de que Ziblatt e Levitsky não questionam a própria democracia em si. Ou seja, é possível considerar um país que exclui a população negra da participação política de forma deliberada como uma democracia? Esta parece ser uma questão válida, pois escancara o caráter antidemocrático do entendimento de democracia presente na obra. Ou seja, na obra, o que garante a existência de uma democracia não é sua extensão participativa, mas sim os pressupostos institucionais, controlados pelas elites e pelos partidos políticos.

Por fim, os autores se propõem a discutir o que se pode fazer para salvar a democracia quando está em perigo, em particular no caso dos Estados Unidos. Mais uma vez, a questão racial aparece como uma urgência, assim como questões identitárias e relacionadas ao aumento da imigração. Outro fator que aparece para ser resolvido é a polarização política extremada entre os dois principais partidos políticos, uma vez que colocam em risco a tolerância mútua e a reserva institucional, consideradas importantes mecanismos de manutenção e proteção da democracia.

Para tal, os autores identificam o principal problema da democracia dos Estados Unidos: a desigualdade social. A resolução desta questão faria com que a polarização e o ressentimento existente em relação as minorias e contra as próprias elites, fenômenos que possibilitaram, ao menos em parte, a eleição de Trump, diminuíssem, tornando possível a reestruturação das barreiras democráticas. Dessa forma, políticas sociais como o acesso a previdência, ao programa Medcare, a renda básica, o acesso à educação, programas de geração de emprego e de formação profissional, entre outras, ajudariam a "reduzir a desigualdade econômica que abastece ressentimentos e polarizações, mas também pode contribuir para a formação de uma coalização ampla durável que realinhe a política norte-americana" (2018, p. 216). Para os autores, é "uma questão de justiça social. A própria saúde da nossa democracia depende disso" (2018, p. 217).

O reconhecimento de que a desigualdade social cumpre um papel importante no esgarçamento da democracia nos Estados Unidos e a defesa de programas sociais que ajudem a diminuir tal desigualdade busca aproximar a definição elitista de democracia adotada na obra de uma base social. No entanto, a análise estritamente politicista e institucionalista que 
os autores fazem da realidade e da democracia impede que estes identifiquem uma contradição insolúvel nas propostas de justiça social para salvar a democracia.

Desde a década de 1970, a avalanche neoliberal busca destruir toda e qualquer reminiscência de proteção social oferecida pelo estado, sendo substituída pelos ideais de individualismo, meritocracia e consumo que resultam na mercantilização de todas as instâncias da vida. A própria eleição de Trump representa, em alguma medida, as tensões decorrentes das políticas neoliberais, já que a desigualdade e a concentração de renda atingem patamares nunca antes vistos nos Estados Unidos. Ou seja, se os autores propõem que uma política social que vise a diminuição da desigualdade pode salvar a democracia, estes não levam em consideração que o neoliberalismo é o exato oposto dessa proposta, que dizer, ou se tem democracia ou neoliberalismo.

Para o leitor brasileiro que buscou respostas na obra dos professores de Harvard, o livro parece superficial, já que, apesar de algum esforço, não consegue aproximar a democracia da sociedade, sendo que as explicações para as ameaças a democracia que Trump e Bolsonaro representam são baseadas em aspectos meramente formas e institucionais. Isso não quer dizer que a obra não deve ser lida, mas diferentemente do que costuma acontecer, me parece que as respostas para se entender como "as democracias morrem" podem ser encontradas nas lacunas deixada pelos autores, ou seja, nos limites, e não nas virtudes da democracia liberal estadunidense, e na incompatibilidade da democracia e do neoliberalismo.

Como citar:

SALGADO, Tiago Santos. Os limites da democracia dos Estados Unidos. Verinotio - Revista on-line de Filosofia e Ciências Humanas, Rio das Ostras, v. 25, n. 1, pp. 340-44, abr. 2019.

Data de envio: 20 jan. 2019 Data de aceite: 15 mar. 2019 